\section{THE ROYAL SOCIETY MEDALS}

$A^{\prime} T$ the conclusion of his anniversary address on Tuesday last week, the President, Mr. Spottiswoode, delivered the medals whick have been awarded this year, and in doing so spoke as follows :-

The Copley Medal has been awarded to Prof, James Joseph Sylvester, F.R.S. His extensive and profound researches in pure mathematics, especially his contributions to the Theory of Invariants and Covariants, to the Theory of Numbers, and to Modern Geometry, may be regarded as fully establishing Mr. Sylvester's claim to the award of the Copley Medal.

One Royal Medal has been awarded to Prof. Joseph Lister, F.R.S. Mr. Lister's claims to the honour of a Royal Medal are based upon his numerous and valuable contributions to physiological and biological science during the last thirty years.

By permission of its author, the Fellow of the Society best qualified, by his own extensive researches on the germ theory, to form a judgment, I quote the following account of Prof. Lister's work and achievements :-

"In 1836 and 1837 it was proved independently by Cagniard de la Tour and Schwann, that vinous fermentation was due to the growth and multiplication of a microscopic plant. At the same time Schwann described experiments which illustrated and explained the conditions, now well known, by which flesh may be preserved from putrefaction. But Schwann's researches were overshadowed by the views of accepted authorities, and they continued so up to the publication of Pasteur's investigations. From this point forward the view gained ground that putrefaction is the work of floating microscopic organisms ; and that if air be thoroughly cleansed of its suspended particles, neither its oxygen, nor any other gaseous constituent, is competent to provoke either fermentation or putrefaction.

"Condensed into a single sentence, the merit of Mr. Lister consists in the generalisation, to living matter, of the results obtained by Schwann and Pasteur with dead matter. He began with cases of compound fracture and with abscesses. In simple fracture the wound is internal, the uninjured skin forming a protecting envelope. Here nature works the cure after the proper setting of the injured parts. In compound fracture, on the other hand, the wound extends to the surface, where it comes in contact with the air; and here the operator can never be sure that the most consummate skill will not be neutralised by subsequent putrefaction.

"In the earliest of his published communications Mr. Lister clearly enunciates, and illustrates by cases of a very impressive character, the scientific principles upon which the antiseptic system rests. He refers to the researches of Pasteur, and shows their bearing upon surgery. $\mathrm{He}$ points to the representative fact, then known but unexplained, that when a lung is wounded by a fractured rib, though the blood is copiously mixed with air, no inflammatory disturbance supervenes; while an external wound penetrating the chest, if it remains open, infallibly causes dangerous suppurative pleurisy. In the latter case the blood and serum are decomposed by the microscopic progeny of the germs which enter with the air; in the former case the air is filtered in the bronchial tubes, and all solid particles are arrested. Three years subsequently this inference of Prof. Lister was shown to be capable of experimental demonstration.

"After enunciating the theoretic views which guided him, he thus expresses himself in his first paper :-

" Applying these principles to the treatment of compound fracture; bearing in mind that it is from the vitality of the atmospheric particles that all the mischief arises, it appears that all that is requisite is to dress the wound with some material capable of killing these sep-ic germs, provided that any substance can be found reliable for this purpose, yet not too potent as a caustic.

"This is the thesis to the illustration and defence of which Prof. Lister has devoted himself for the last thirteen years. His thoughts and practice during this time have been in a state of growth. His insight has been progressive; and the improvement of experimental methods founded on that insight incessant. By contributions of a purely scientific character, which stamp their author as an accomplished experimenter, he has materially augmented our knowledge of the most minute forms of life. The titles of his papers indicate the direction of his labours from time to time; but they give no notion of the difficulties which he has encountered, and successfully overcome. He performs, without dread of evil consequences, the most dangerous opera tions. He ventures fearlessly upon treatment which, prior to the introduction of his system, would have been regarded as ne less than criminal. In the Crlasgow Royal Infirmary, when wards adjacent to his had to be abandoned, he operated with success in an atmosphere of deadly infectiveness. Vividly realising the character and habits of the 'invisible enemy' with which he bas to cope, his precautions are minute and severe. This demand for exactitude of manipulation has rendered the acceptance of the Antiseptic System slower than it would otherwise have been ; but a clear theoretic conception has this value among others : it renders pleasant a minuteness of precaution which would be intolerable were its reasons unknown.

"The operative surgeons of our day have raised their art to the highest pitch of efficiency. Their skill and daring are alike marvellous. Mr. Lister urges an extension of this skill from the operation to the subsequent treatment, contending that every surgeon ought to be so convinced of the greatness of the benefits within his reach as to be induced to devote to the dressing of wounds the same kind of thought and pains which he now devotes to the planning and execution of an operation. His impressive earnestness; his clearness of exposition; his philosophic grasp of the principles on which his practice is founded-above all his demonstrated success-have borne their natural fruit in securing for him the recognition and esteem of the best intellects of the age.

"In a letter addressed to the writer on the 29th of September, 1880, Prof. Helmholtz expresses himself thus :-

" 'Prof. Lister ist als einer der hervorragendsten Wohlthäter der Menschheit $2 \mathrm{u}$ betrachten, und als eines der glänzendsten Beispiele, wie segensreich scheinbar minutiöse und abstruse wissenschaftliche Untersuchungen, wie die ïber di Erzeugung mikroskopischer Organismen, werden können, wenn sie von einem Manne von umfassendem geistigen Gesichtskreise aufgenommen werden.'"

"In a letter dated October Ist, I88o, Prof. Du Bois Raymond wiites :-

" "The period of blcody warfare through which we passed not long ago, just when Prof. Lister's methods were matured enough to be freely used even on the battlefield, has of course contributed to render his name popular throughout Germany; nay, to make it a household word in many homes. We use the word 'listern' as a verb to designate the use of the carbolspray while bandaging a wound. I do not hesitate to proclaim Lister the greatest benefactor of mankind since Jenner's wonderful discovery-far superior, indeed, to Jackson and Simpson because, whatever may be the dread of pain and the blessing of being spared it, in Lister's invention health and life itself are concerned, as in hardly any other medical discovery except vaccination. Moreover, the general ideas which have led to Prof Lister's conception stamp his work with a peculiarly scientific character.

"In a letter dated from Vevey on the roth of this month, Prof. Klebs of Prague, bimself a distinguished worker in this field, expresses in the strongest terms his admiration of the profound philosophical intuition and practical success of Mr. Lister, as having not only reformed the whole art of surgery, but given a new impulse to medical science generally. Prof. Klebs's interpretation of the opposition encountered for a time by Mr. Lister is worthy of mention. He ascribes it to the high standard attained by British surgery before the time of Lister. 'The operators,' he says, 'that work under the best hygienic conditions will not feel so acutely as others do the necessity of disinfecting wounds. But the good results of the former British surgery are now surpassed by the new method, which is accepted at the present time by the whole world.'

"Such testimonies might be multiplied to any extent. The foregoing are the answers received from the only three gentlemen who have been requested to expres $\mathrm{S}$ an opinion as to the merits of Mr. Lister.'

The second Royal Medal has been awarded to Capt. Andrew Noble, late R.A., F.R.S. Capt. Noble is joint author with Prof. Abel of the "Researches on Explosives," Phil. Trans., 1875, which, in combination with other labours in the same field, procured for Prof. Abel the honour of the Royal Medal in 1879 . To Prof. Abel is due mainly the chemical part of these investigations; to Capt. Noble the mechanical and mathematical part. Each is a complement of the other, but it 
may be safely affirmed that they could not have been presented to the world in the form in which they appear without the cooperation of his remarkable union of technical knowledge and mastery of mathematical analysis with the chemical science of Prof. Abel. His beautiful invention of the Chronoscope, an instrament constructed by nim at great cost, by which intervals of time as small as the one-millionth part of a second can be measured, has been of indispensable value in these researches. $\mathrm{He}$ is the author of papers which have been translated into most European languages on subjects of gunnery and gunpowder; he is perhaps the highest authority we possess on the higher branches of artillery science, and the best known on the Continent. His great talents and attainments are not more conspicuous than his singular modesty and his indefatigable industry. He has been engaged on these subjects about twenty years, having published the first experiments in this country with Navez' electroballistic apparatus, in 1862.

The Rumford Medal has been awarded to Dr. William Huggins, F.R.S. In 1866 a Royal Medal was awarded to Dr. Huggins for his important researches. Since that time he has been continually engaged in prosecuting the subject of celestial spectroscopy, both in the departments in which he had already done so much, and in others of its branches. One subject of Dr. Huggins' researches relates to the determination of the radial component of the velocity of the heavenly bodies relatively to our earth, by means of the alteration of the refrangibility of certain definite kinds of light which they emit, or which are stopped by their atmospheres. The smallness of the alteration corresponding to a relative velocity comparable with the velocity of the earth in its orbit makes the determination a matter of extreme delicacy. But as early as 1868 he had obtained such trustworthy determinations that he was able to announce before the Royal Society in that year that Sirius was receding from our solar system with a velocity of about $29^{\circ} 94$ miles per second.

In a paper presented to the Royal Society in 1872 be has given the results obtained for a large number of stars, and has shown that some are receding and some approaching, and that there seems to be a balance of recession in those parts of the heavens, from which we have reason, from the observed proper motions, which of course can only be transversal, to conclude that the solar system is receding, and a balance in favour of approach in the opposite direction; while yet it does not appear that the motion of the solar system would alone account for the whole of the proper motions of the stars in a radial direction.

The same inquiry was extended to the nebulæ, the spectrum of which consists of bright lines, and in this case it presented greater difficulties. As those nebular lines which appear pretty certainly to be identifiable with hydrogen are too faint to be employed in the investigation, and the others are not at present identified with those of any known element or compound, he was obliged to avail himself of a coincidence between the brightest nebular line and a line of lead. But as the coincidence is probably merely fortuitous, the results give only the differences of approach or recess of different nebulæ. The observations seem to show that, so far as has been observed, the nebulx are objects of greater fixity as regards motion in space, than the stars.

The other subject to which Dr. Huggins has more particularly devoted himself of late, is the mapping of the photographic spectra of stars. This was a research of great delicacy, partly on account of the small quantity of light at the disposal of the observer, partly from the great accuracy with which the comparison had to be made with the spectra of known substances, in order that satisfactory conclisions should be deducible as to the presence or absence of such or such substances in the stars. The results obtained led to a remarkable division of the stars into two great classes, naturally with transition cases, namely, white stars, which showed a group of twelve dark lines belonging, apparently, to the same substance, probably hydrogen, and the group of stars, of which our own sun may be taken as a type.

Besides the researches already mentioned, other papers have been presented by Dr. Huggins to the Royal Society, on the spectra of comets, on the spectrum of Uranus; and in particular one in which he showed that it was possible to detect the heat of the stars, and has given the results obtained for several.

The Davy Medal has been awarded to Prof. Charles Friedel, Member of the Institute of France.
From 1856 to the present time the investigations of M. Charles Friedel, ranging over widely-remote fields of chemical inquiry, have been continuous, numerous, and important. Mineralogical, theoretical, and general chemistry are indebted to him for many valuable contributions; but it is in the department of so-called organic chemistry that he has more especially laboured; and herein he has done much to assist in breaking down the barriers at one time regarded as impassably isolating the chemistry of carbon compounds.

Among the subjects of M. Friedel's successful work may be mentioned more particularly the chemistry of the 3 -carbon family of organic bodies, to which belong propionic acid, lactic acid, glycerine, propylene, and acetone. The establishment of the constitution of lactic acid and of acetone, with the determination of the relationships to one another of the various, and in many cases isomeric, members of this large family, constituted for a long time one of the most fiercely-contested, as it was, and is, one of the most fundamental problems of organic chemistry. In the labours effecting the satisfactory solution of this problem M. Friedel bore a large share.

Passing to another branch of investigation, M. Friedel, partly by himself, but largely in conjunction in some parts of the work with Mr. J. M. Crafts, and in other parts with M. A. Ladenburg, made out, or confirmed in a very striking manner, the analogy subsisting between the modes of combination of carbon and of silicon, the most characteristic elements of the organic and inorganic kingdoms respectively.

To mention but one more subject of $M$. Friedel's research, he has, in conjunction with Mr. J. M. Crafts, made out and defined a simple method of wide application for effecting the synthesis of organic compounds. This method consists in bringing together a hydrocarbon and an organic chloride in presence of chloride of aluminum, whereby the residues of the two com. pounds enter into combination to form a more complex, frequently a bighly complex, body. Independently of its utility, this process of synthesis is of remarkable interest from the part taken in it by the chloride of aluminum, which, though essential to the reaction, is found unaltered at the end, and seems to act by suffering continuously, little by little, a correlative transformation and regeneration.

\section{UNIVERSITY AND EDUCATIONAL} INTELLIGENCE

OXFORD.- The statutes made by the new Commissioners for the different colleges are appearing in their final shape. The statutes of six colleges are already printed and in the hands of Members of Convocation. They resemble each other closely in several respects. Ordinary Fellows are to be elected by examination, all the branches of learning recogniised in the final schools of the University being taken from time to time as the subject of examination. These Fellowships are tenable for seven years. Tutorial Fellows are elected withont examination, but the colleges may require two years' college work from an ordinary Fellow, having given notice of such requirement before the examination. The colleges may elect persons distinguished in literary or scientific work to Fellowships tenable for a term of years, during which the Fellows shall devote themselves to a definite research specified in the resolution appointing them.

Several meetings of the Professors and College Tutors engaged in teaching different branches of Physics in the University have been held during the last fortnight at the instance of Prof. Clifton. The object was to prepare a scheme of lectures for next term, such that the lecturers would cover most of the ground without clashing with each other or with the lecturers in other branches of science. It may be mentioned that this is the first time such an arrangement has been arrived at in the Natural Science School at Oxford. The following plan of lectures has been agreed upon for next Lent Term :-

Optics (treated Mathematically), Prof. Price, Tuesday, Thursday, and Saturday, at 12; Magnetism (treated experimentally), Prof. Clifton, Wednesday and Saturday, at 12; Practical Physics, Prof. Clifton, Mr. Stocker, Mr. Jones, daily, i I a.m. to 4 p.m. Thermodynamics and Electrodynamics (treated mathematically), Mr. Baynes, Monday, Wednesday, and Friday, at ro; Electrostatics (treated mathematically), Mr. Hayes, Saturday at II ; Elementary Mechanics (treated experimentally), Mr. Stocker, Monday and Wednesday, at 10; Problems in Elementary Mechanics and Physics, Mr. Jones, Friday, at 10; Elementary Physics (treated experimentally), Mr. Dixon, Monday, Wednes. 